Please do not remove this page

RMIT

UNIVERSITY

\title{
The harnessing of peptide-monolith constructs for single step plasmid DNA purification
}

Han, Ying; You, Guanlin; Pattenden, Leonard; Forde, Gareth

https://researchrepository.rmit.edu.au/esploro/outputs/9921857928301341/filesAndLinks?institution=61RMIT_INST\&index=null

Han, Y., You, G., Pattenden, L., \& Forde, G. (2010). The harnessing of peptide-monolith constructs for single step plasmid DNA purification. Process Biochemistry, 45(2), 203-209.

https://doi.org/10.1016/j.procbio.2009.09.008

Document Version: Accepted Manuscript

Published Version: https://doi.org/10.1016/j.procbio.2009.09.008

Repository homepage: https://researchrepository.rmit.edu.au

(c) 2009 Elsevier Ltd. All rights reserved.

Downloaded On 2023/04/26 22:57:22 +1000

Please do not remove this page 
Citation:

Han, Y, You, G, Pattenden, L and Forde, G 2010, 'The harnessing of peptide-monolith constructs for single step plasmid DNA purification', Process Biochemistry, vol. 45, no. 2, pp. 203-209.

\section{Accepted Manuscript}

Title: The Harnessing of Peptide-Monolith Constructs for Single Step Plasmid DNA Purification

Authors: Ying Han, Guanlin You, Leonard K. Pattenden, Gareth M. Forde

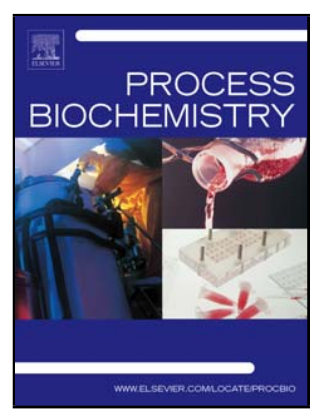

PII:

DOI:

Reference:

To appear in:

Received date:

Revised date:

Accepted date:
S1359-5113(09)00286-4 doi:10.1016/j.procbio.2009.09.008 PRBI 8745

Process Biochemistry

8-9-2009

Please cite this article as: Han Y, You G, Pattenden LK, Forde GM, The Harnessing of Peptide-Monolith Constructs for Single Step Plasmid DNA Purification, Process Biochemistry (2008), doi:10.1016/j.procbio.2009.09.008

This is a PDF file of an unedited manuscript that has been accepted for publication. As a service to our customers we are providing this early version of the manuscript. The manuscript will undergo copyediting, typesetting, and review of the resulting proof before it is published in its final form. Please note that during the production process errors may be discovered which could affect the content, and all legal disclaimers that apply to the journal pertain. 


\section{The Harnessing of Peptide-Monolith Constructs for Single Step Plasmid DNA Purification}

Ying Han ${ }^{\mathrm{a}^{*}}$, Guanlin You ${ }^{\mathrm{b}}$, Leonard K. Pattenden ${ }^{\mathrm{c}}$, Gareth M. Forde ${ }^{\mathrm{a}}$

a. Bio Engineering Laboratory, Department of Chemical Engineering, Monash University, Vic 3800, Australia.

b. School of Engineering, University of Ballarat, Mt Helen, Vic 3350, Australia

c. Health Innovations Research Institute, School of Medical Sciences, RMIT University, PO Box 71, Bundoora, Vic 3083, Australia.

* Corresponding author: ying.han@eng.monash.edu.au

Key words: Affinity ligands, Chromatography, DNA purification, Monolith, Plasmid DNA, Process scale up, Protein-DNA binding. 


\begin{abstract}
The availability of synthetic peptides has paved the way for their use in tailor-made interactions with biomolecules. In this study, a 16mer LacI-based peptide was used as an affinity ligand to examine the scale up feasibility for plasmid DNA purification. First, the peptide was designed and characterized for the affinity purification of $l a c \mathrm{O}$ containing plasmid DNA, to be employed as a high affinity ligand for the potential capturing of plasmid DNA in a single unit operation. It was found there were no discernible interactions with a control plasmid that did not encode the lac $\mathrm{O}$ nucleotide sequence. The dissociation equilibrium constant of the binding between the 16 mer peptide and target pUC19 was $5.0 \pm 0.5 \times 10^{-8} \mathrm{M}$ as assessed by surface plasmon resonance. This selectivity and moderated affinity indicate that the $16 \mathrm{mer}$ is suitable for the adsorption and chromatographic purification of plasmid DNA. The suitability of this peptide was then evaluated using a chromatography system with the 16 mer peptide immobilized to a customized monolith to purify plasmid DNA, obtaining preferential purification of supercoiled pUC19. The results demonstrate the applicability of peptide-monolith supports to scale up the purification process for plasmid DNA using designed ligands via a biomimetic approach.
\end{abstract}




\section{Introduction}

The current high level of interest in structural biology information coupled with the growing demand for high purity DNA, employed as vaccines and gene therapies, has led to an interest in harnessing naturally occurring DNA affinity interactions for use in DNA purification and detection applications [1-9]. Furthermore, the stringent purity requirements of regulatory bodies (i.e. FDA, EMEA, TGA) [10] creates a demand for methods to obtain very pure bio-therapeutics or biopharmaceuticals without contaminants. This demand is particularly strong for plasmid DNA (pDNA), which has potential in the bio-pharmaceutical industry for the expression of therapeutic proteins and peptides in vivo and as a vaccine [5].

The production of pDNA is often accomplished by lysis of the cells, followed by a clarification/concentration step and, finally, three or more chromatography steps [11-17] to remove host cell contaminants: RNA, proteins, endotoxins and genomic DNA (gDNA), which may constitute as much as $98 \%$ of material by dry weight. Affinity chromatography can be used to specifically capture target product (pDNA) and isolate it based on specific biological function or individual chemical structure, thus having the power to reduce downstream processing when the selectivity and binding strength of optimised affinity ligands enable an otherwise multi-step purification procedure to be replaced by a single affinity purification step. However, no affinity purification protocol can be utilised without suitable ligands [18], and this is especially important to meet with the demands and rigours of industry requirements. 
Several ligands for affinity purification of pDNA have been investigated at the laboratory scale. The formation of triple helices between oligonucleotides attached to a chromatographic matrix and duplex sequences (present on the plasmid) has been used to purify pDNA [19, 20]. In these reports, more than $60 \%$ recovery yields were reached and the RNA and gDNA content were reduced significantly, but slow binding kinetics were displayed creating a limitation at scale [19, 20]. Studies using proteins as affinity ligands to purify pDNA have also been described such as a zinc finger DNA-binding protein [21] and Lac repressor protein $[22,23]$. Although effective, there is a limitation of scale and economics as such ligands are large and often challenging to purify.

Despite these limitations, the application of the Lac repressor protein in displacement chromatography was shown to retain biological activity after immobilization [24]. Hasche and Voß (2005) found that interaction between repressor molecules in the form of a short operator sequence was specific for double stranded DNA, with no RNA interactions being detected [25]. The Lac repressor (lacI) is a DNA binding protein that regulates expression of the lac operon. LacI has been studied extensively at the genetic and structural level [26-33]. From the structure of the protein and DNA complex (Figures 1 and 2, the Protein Database entry the code 1JWL), the DNA binding domain consists of helix I (residues 7 to 13), a turn, helix II (17 to 26), helix III (33 to 47), and the hinge helix IV (50 to 59). Within LacI, this domain binds to DNA that is formed through association of the $\sim 300$ amino acid residue at C-terminal domain. The binding is a complex interaction of hydrophobic interactions and hydrogen bonding [26].

Because of the well-characterised and favourable properties, LacI-based approaches have also been described for affinity adsorption of pDNA, however the yield of pDNA was low [22, 23, 34]. One contributing factor was the strong binding between pDNA and ligands. Ideally, the binding should 
be strong enough to avoid leakage during the pDNA application and wash phases, whilst enabling complete release of pDNA during the elution phase. The optimal dissociation constant for an affinity binding mechanism for use in a chromatographic system lies in the approximate range of $10^{-6}-10^{-8} \mathrm{M}$ and is the range for many affinity chromatography systems (e.g. maltodextrin-maltose binding protein $\left(10^{-7} \mathrm{M}\right)$, Calmodulin chromatography $\left(10^{-8} \mathrm{M}\right)$ ) and is the target range for engineered systems where native binding affinities are too high for elution (e.g. Softlink ${ }^{\mathrm{TM}}$ avidin $\left(10^{-7} \mathrm{M}\right)$, Strep-Tactin ${ }^{\circledR}$ superflow $\left.\left(10^{-6} \mathrm{M}\right)\right)$. This range allows designed peptides to rapidly bind with suitable affinity for pDNA, selectivity of the target pDNA without the co-purification of other biomolecules (gDNA, RNA, protein, and endotoxins), and tight binding sufficient for process rigours but appropriate for elution from the matrix.

For this purpose, the naturally occurring binding of $l a c \mathrm{O} / \mathrm{LacI}$ was optimized for purification of pDNA. As previously reported, synthetic peptides based on the Lac repressor protein (lacI) strongly bind pDNA containing lacO sequences [5]. In order to obtain lacO-binding peptides that bind with suitable affinity, we reasoned that deletion of some non-contributing amino acids could create a peptide that retains the DNA binding properties of the Lac repressor.

The sequence chosen for the 16mer peptide utilizes a portion of the helix II DNA binding domain of the Lac repressor (-TVSRVVNQ-) as reported from the crystal structure (Bell and Lewis 2001). Nterminal to this fragment is a designed sequence (NH-CMKYVSHG-) which is predicted to provide a coil-like secondary structure to this region of the peptide, supportive of the natural helicity of the DNA binding domain (Fig. 1 and 2), while also providing a spacer from chromatography matrices. The cysteine residue is important for attachment to biosensor and chromatographic supports and provides known chemical manipulation such as coupling or heterobiofunctional modification. 
The designed portion also imparts favourable chromatography-relevant physicochemical properties for the entire 16mer peptide [35] relevant to scaled use in chromatography such as economics and regeneration; the molecular weight is low ( $\mathrm{mw} 1808.1 \mathrm{amu}$ ) being economical to manufacture, the $\mathrm{pI}$ is not excessively high (pI 9.31) as often seen for DNA binding entities which can be problematic for chemical attachment or behaviour on supports. The aliphatic index contributed by the relative volumes of the four valine residues is reasonably high $(72.5 \%)$ which is regarded as a positive factor for thermostability and refolding $[35,36]$, and the grand average of hydropathicity (GRAVY), which is a hydropathic summation of all residues, indicates a soluble peptide $(-0.087)$ [37]. These facets favour the refolding of the peptide, which may include harsh regeneration conditions without collapse or precipitation on the surface of the column.

This study tested the utility of the designed 16 mer peptide as an affinity ligand immobilized on a customized monolith to purify pUC19 pDNA containing a lac $\mathrm{O}$ nucleotide sequence. In an engineering context, the potential of process scale up is always one of primary concern. Highdensity bacterial lysates produced from bioreactors are very viscous and the desired pDNA are large molecules, causing significant process complexities at scale. The purification of large polynucleotides such as pDNA is hampered by the performance of conventional particulate chromatographic supports. Most of these particulate supports are made for small molecules and proteins, typically targeting molecules with diameter less than $10 \mathrm{~nm}$ [38]. In columns packed with such supports, large molecules such as pDNA with a size of $100 \mathrm{~nm}$ to over $300 \mathrm{~nm}$ in diameter adsorb predominantly at the beads outer surface [39]. Thus, the pore characteristics of chromatographic supports need to be considered for applications where the target molecules are several orders of magnitude larger than standard molecules typically applied to the columns. The 
large pores of monoliths will allow penetration of large pDNA molecules to the internal surface area at high flow rate with low pressure drops [40-45]. Polymethacrylate monolithic supports are optimal adsorbents for large biomolecule separation. These adsorbents have large pore diameters and can be easily modified by functionalising with affinity ligand [15-17, 20, 46, 47]. Monolithic systems are particularly attractive for pDNA purification; the surface characteristics are inert to the target pDNA molecule and many contaminants, it is simple to tailor monolithic pore sizes (through alteration in synthesis conditions) and naturally the scalability favours industrial processes [47]. We therefore sought to test the modified lacI based 16mer peptide for affinity pDNA purification using peptide-monolith constructs, which included the synthesis and engineering of poly(glycidyl methacrylate-co-ethylene glycol dimethacrylate) monoliths. The ultimate goal of this study is to assess the applicability of peptide-monoliths for the scale up of pDNA purification processes.

\section{Material and Methods}

\subsection{Material/Instruments}

N-hydroxysuccinmide (NHS), N-ethyl-N' - (3- diethlamino propyl) carbodiimide hydrochloride (EDC), sensor chip $\mathrm{C} 1$ (research grade) and HBS-EP buffer $\mathrm{pH} 7.4$ were purchased from GE Healthcare (Biacore, Sweden); Agarose (Promega), freezer (Nuaire), centrifuge (Heraeus), Wizard Maxipreps DNA Purification System (Promega), electrophoresis gel analyser (Bio-rad) and spectrophotometer (Shimadzu), Ethylene glycol dimethacrylate (EDMA), glycidyl methacrylate (GMA), ethylenediaminetetraacetic acid (EDTA), sodium chloride, sodium hydroxide, ethidium bromide and other chemicals were purchased from Sigma-Aldrich (St. Louis, MO) and of analytical grade if not stated otherwise. 


\subsection{Plasmid DNA and cultivations of bacteria}

Plasmid pUC19 $(0.01 \mu \mathrm{g} / \mathrm{l})$ purchased from Invitrogen was transformed and propagated in E. coli DH5 $\alpha$ (EndA ${ }^{-}$from Invitrogen) in a 17 L fermentor (Bioflow 410, New Brunswick Scientific, USA). A culture of $E$. coli DH5 $\alpha$ was grown in LB medium supplemented with $100 \mu \mathrm{g} / \mathrm{ml}$ ampicillin (Austrapen) and was incubated overnight at $37{ }^{\circ} \mathrm{C}$. Unused cells were refrozen in a dry ice/ethanol bath for 5 minutes before returning to the $-75^{\circ} \mathrm{C}$ freezer (Nuaire, ultralow freezer, Japan).

DH5 alpha is a k12 derivative and has the genotype: F- (80lacZ $\Delta$ M15 $\Delta$ (lacZYA-argF) U169 recA1 endA1 hsdR17 (rK-, mK+) phoA supE44 $\lambda-$ thi-1 gyrA96 relA1. Therefore, DH5 $\alpha$ has the normal and fully functional genomic lac operon of E. coli. The lambdoid prophage (Ф80lacZ $\Delta \mathrm{M} 15$ $\Delta(\operatorname{lacZYA}-\operatorname{argF}) \mathrm{U169}$ ) is a defective phage carrying the lacZM15 deletion (as well as wild-type lacI, lacYA, and flanking sequences). As such, DH5 $\alpha$ has additional lac operon genes present as part of the blue-white screening phenotype, including lacI.

On a technical note: some strains of DNA-propagating E.coli phenotypically over-express lacI. Specifically strains that contain $\operatorname{lacI}^{\mathrm{q}} / \mathrm{lacI}^{\mathrm{Q}}$ and $\mathrm{lacI}^{\mathrm{Q} 1}$ have a phenotype for overproduction of lacI governed by mutations in the upstream promoter site (-35 GCGCAA to GTGCAA or a 15 bp deletion respectively), creating an optimal promoter upstream of lacI and leading to constitutive expression. However, similar to DH5 $\alpha$ used here, this is subject to growth and process conditions and can be optimized and controlled just like any other process parameter. I.e. preparation of lysates in preceding unit operations prior to chromatography using conditions that dissociate protein-DNA complexes or manipulation of standard lac operon conditions by controlled media and reactor 
conditions (e.g. cAMP levels, CAP protein concentrations, lactose presence/absence, glucose presence/absence and IPTG presence/absence).

\subsection{Isolation of pDNA and spectroscopy}

Control Plasmid pEGFP-N1 and assay pUC19 were produced via the use of the Promega Wizard ${ }^{\mathrm{TM}}$ Plus Maxiprep DNA purification System (Promega, USA) with purification protocols for high copy number vectors according to the instructions of the manufacturer. Cell culture $(250 \mathrm{ml})$ was used for pDNA purification each time. The purified pDNA was used to characterise the interaction of the designed 16mer peptide with DNA. TE buffer (10 mM Tris-HCl, 1 mM EDTA), pH 8.0 was used in DNA ladder dilutions. DNA concentrations were determined using UV spectroscopy at 260nm $\left(\mathrm{A}_{260}\right)$. All sample used had an initial $\mathrm{A}_{260} / \mathrm{A}_{280}$ ration between 1.7 and 1.9.

\section{4. $p E G F P-N 1$}

In order to investigate the binding specificity of the lac operon (lac $\mathrm{O})$ sequence contained in the pDNA and its repressor, the lacI protein, another plasmid DNA that does not contain the lacO sequence used in this research was pEGFP-N1 (Clontech laboratories, CA, USA), a $4733 \mathrm{~kb}$ plasmid encoding an enhanced green fluorescence protein. Plasmid pEGFP-N1 was purified from JM109 E-coli cells. The molecular weight of pEGFP-N1 was $2.924 \times 10^{6} \mathrm{~g} / \mathrm{mol}$.

The plasmid pEGFP-N1 was selected to conduct a control experiment with the 16mer peptide. From comparison of the restriction map and multiple cloning sites (MCS) of pEGFP-N1 and pUC19 vectors, all restriction sites used in this study are unique 
(http://www.pkclab.org/PKC/vector/pEFGPN1.pdf). Its backbone provides a pUC origin of replication for propagation in E. coli. However, the alignment results from the Matcher program (http://www.ba.itb.cnr.it/BIG/PatSearch/) confirm that there is no identical sequence of $\operatorname{lac}_{1}$ and lac $\mathrm{O}_{3}$ in pEGFP-N1 or in pUC19 and similar segment sequences of DNA are not homologous to the important region where lacI helix II binds.

\subsection{Gel electrophoresis}

The integrity of pDNA and change in the proportion of isoforms was assessed by gel electrophoresis. $0.8 \%$ agarose gels were used with a $1 \mathrm{~kb}$ DNA ladder (Promega, USA) as a marker with fragments of $10,8,6,5,4,3,2,1.5,1$ and $0.5 \mathrm{kbp}$. Every sample (350 $\mu \mathrm{g}$ DNA loaded) was loaded as indicated in the results section onto the $0.8 \%$ agarose gel containing $0.05 \mu \mathrm{g} / \mathrm{ml}$ ethidium bromide and electrophoresised at $66 \mathrm{~V}$ for 90 mins in TAE (Tris-acetate electrophoresis buffer (10 $\mathrm{mM}$ Tris, $10 \mathrm{mM}$ acetate acid, $1 \mathrm{mM}$ EDTA)). All the gels were scanned and analysed using Quantity One ${ }^{\mathrm{TM}}$ gel documentation and densitometric system (Bio-rad laboratories Inc., CA, USA).

\subsection{Restriction endonuclease digestion of purified pDNA}

Plasmid DNA (pUC19) was treated with EcoRI. Following digestion, the various forms of pUC19 DNA was separated by agarose gel electrophoresis in the presence of ethidium bromide. The gel was visualized under UV light and the image recorded for later interpretation.

\subsection{LacI Peptide}


The 16mer peptide was custom synthesized under contract by Mimotopes Pty Ltd. (Melbourne, Australia). This 16 amino acid residue oligopeptide (NH-CMKYVSHGTVSRVVNQ-COOH), comprises a DNA-binding domain of Helix II from the LacI protein -TVSRVVNQ-. The peptide sequence and secondary structure prediction appears in Fig. 1 and its schematic presentation within the lacI protein is shown in Fig. 2 based on the protein database entry 1JWL, which demonstrates the helical nature of the lacI protein and feasibility of utilising Helix II due to the extensive bonding and deep penetration of the peptide that is expected based on this high-resolution crystal structure.

\subsection{Surface plasmon resonance analysis}

Surface Plasmid Resonance (SPR) assays were performed as previously described [48]. Biacore X and C1 sensor chip were both supplied by GE Healthcare (Biacore - Uppsala, Sweden). Biacore experiments were performed with Hepes-buffered saline (HBS pH 7.4) as a running buffer $(0.01 \mathrm{M}$ HEPES pH 7.4, 0.15 M NaCl, 3 mM EDTA, 0.005\% Surfactant P20, sterile-filtered and degassed). The pDNA binding was monitored using a flow rate of $30 \mu 1 /$ min and the sensor chip surface was regenerated after each experiment by several injections of $30 \mu \mathrm{l}$ of $1 \mathrm{M} \mathrm{NaCl}(\mathrm{pH} 10)$. The principle and application of the system employing the method of SPR detection is well described [49]. Coupling of the 16mer peptide to the sensor chip $\mathrm{C} 1$ utilised the $\mathrm{N}$-terminal cysteine and the ligand thiol method as described $[48,50]$.

The immobilisation of peptide was performed using $90 \mu 1$ of PDEA in borate buffer $\mathrm{pH} 8.3$ on the carboxymethalyted matrix activated with $50 \mu \mathrm{l}$ of a mixture of $0.2 \mathrm{M}$ EDC and $0.05 \mathrm{M}$ NHS. Then, $90 \mu 1$ of the peptide $(200 \mu \mathrm{g} / \mathrm{ml}$ in Formate buffer, $\mathrm{pH} 4.3)$ was applied to flow cell No. 2 of each 
sensor chip C1. Flow cell No.1 was kept free of peptide solution and acted as reference cell in the test procedure. After immobilization both sensor chips were blocked by serial injection of Lcysteine $(20 \mu \mathrm{l}$ of $50 \mathrm{mM})$ onto both flow cells. The immobilization procedure of the $16 \mathrm{mer}$ peptide is provided in Fig. 3.

\subsection{Binding of dsDNA to immobilized LacI peptide}

The control dsDNA purified using the plasmid mini-prep kit was diluted with HBS buffer, $\mathrm{pH}$ 7.4. Serial dilutions of the pDNA were loaded onto the Biacore $\mathrm{C} 1$ chip. Based on the SPR principle, when molecules in the sample bind to the sensor surface, the concentration and therefore the refractive index at the surface changes and a SPR response is detected. All biosensor data was studied using steady-state affinity analysis using BIAevaluation software (version 4.1 - Biacore, Uppsala Sweden).

Analysis was conducted assuming a Langmuir (1:1 model), where one analyte interacts with one ligand to form a complex on the surface. In biosensor terms, the free species is described as the analyte "A" and is pDNA in these experiments. The immobilised ligand (the 16mer lacI peptide) on the sensor surface is described as species " $\mathrm{B}$ " that subsequently interact to form the combined "AB" complex.

The maximum binding capacity ( $\operatorname{Rmax})$ where $100 \%$ of all the immobilised ligand $\mathrm{B}$ is saturated with the analyte A to form the AB complex was calculated as follows:

$$
R \max (R U)=\underline{\text { analyte } \mathrm{mw}} \mathrm{x} \text { immobilisation level }(\mathrm{RU}) \mathrm{x} \text { stoichiometry }
$$




\section{ligand $\mathrm{mw}$}

The steady-state approximation was then made by plotting Req vs concentration, where Req is the steady state level at a given conventration value. The equilibrium dissociation constant (KD) was then determined as Rmax/2 as shown in figure 5 using the plateau regions of the sensorgrams.

\subsection{Synthesis of monolith and immobilization of peptide}

Synthesis of monolith and immobilization of peptide assays were performed as previously described [51]. Free radical liquid porogenic co-polymerisation of ethylene glycol dimethacrylate (EDMA) and glycidyl methacrylate (GMA) was used to prepare the monolith support. The cyclohexanol/1dodecanol was added into EDMA/GMA mixture as an alcohol-based bi-porogen solvent in the proportion of 50/10/20/20 (cyclohexanol/1-dodecanol/GMA/EDMA) in a total volume of $4 \mathrm{ml}$ mixture. AIBN (1\% weight with respect to monomer) was used to initiate the polymerisation process. The polymer mixture was sonicated for $10 \mathrm{~min}$ and sparged with $\mathrm{N}_{2}$ gas to expel dissolved $\mathrm{O}_{2 .} .4 \mathrm{ml}$ of the mixture was gently transferred into a $12 \mathrm{~cm} \times 1.5 \mathrm{~cm}$ polypropylene column (Biorad) and sealed before placing in a water bath $\left(18 \mathrm{~h}, 50{ }^{\circ} \mathrm{C}\right)$. The polymer was washed to remove all porogens and other soluble materials with methanol. The polymer was washed again with $0.5 \mathrm{M}$ $\mathrm{Na}_{2} \mathrm{CO}_{3}, 1.0 \mathrm{M} \mathrm{NaCl}$, pH 11.5 followed by $50 \mu \mathrm{g} / \mathrm{ml}$ solution of $16 \mathrm{mer}$ peptide in binding buffer (0.1 M Tris-HCl, $\mathrm{pH} 7.5,0.5 \mathrm{M} \mathrm{NaCl}, 1 \mathrm{mM}$ EDTA) and the reaction was allowed to proceed (10 $\mathrm{h}$, $\left.4^{\circ} \mathrm{C}\right)$. The resulting resin was washed with Milli-Q water. The ligand density was found to be $0.03 \mu \mathrm{g} 16 \mathrm{mer}$ peptide/ml monolith by measuring the concentration of peptide in binding buffer before and after immobilization. 


\subsection{Packed Bed Chromatography}

A $12 \mathrm{~cm} \times 1.5 \mathrm{~cm}$ polypropylene column (Biorad) was packed (during the synthesis of methacrylate monolith) with $4 \mathrm{ml}$ of monolith and equilibrated with ten column volumes of PBS buffer. Feed containing the pUC19 pDNA in PBS $(100.2 \mu \mathrm{g}, 0.2 \mathrm{ml})$ was loaded onto the column at a rate of 0.5 $\mathrm{ml} / \mathrm{min}$. The column was then washed with 5 column volumes of PBS buffer and the pUC19 pDNA was eluted with PBS buffer with additional $1 \mathrm{M} \mathrm{NaCl}$ at an increased flow rate of $1 \mathrm{ml} / \mathrm{min}$. The column was operated using Duoflow biological chromatographic system (Biorad, USA), with no pressure changes noted under flow conditions of $0.2,0.5$ and $1 \mathrm{ml} / \mathrm{min}$. All fractions were analyzed by $0.8 \%$ agarose electrophoresis and Picogreen Assay.

\subsection{Column cleaning and regeneration procedure}

The functionalized monolith column was cleaned with a solution containing $0.1 \mathrm{M} \mathrm{NaOH}, 1 \mathrm{M}$ $\mathrm{NaCl}$ and $10 \% \mathrm{EtOH}$ followed by $10 \% \mathrm{EtOH}$ only. The column was then regenerated with $25 \mathrm{mM}$ Tris- $\mathrm{HCl}, 2.0 \mathrm{M} \mathrm{NaCl}, \mathrm{pH} 8.1$ and equilibration was performed with the appropriate starting buffer until a steady UV baseline was obtained.

\subsection{Dynamic binding capacity for pDNA}

A polypropylene column (Biorad, USA) was connected to a Duoflow biological chromatographic unit (Biorad, USA) via an adaptor, and used for determination of pDNA dynamic binding capacity. These experiments were conducted at a flow rate $0.2 \mathrm{ml} / \mathrm{min}$ at room temperature and pDNA concentrations $69.9 \mu \mathrm{g} / \mathrm{ml}$. The column was equilibrated with $0.01 \mathrm{M}$ PBS buffer, $\mathrm{pH}$ 7.4. Recording breakthrough curves and calculating the amount of bound pDNA per ml support at 50\% 
breakthrough provided dynamic binding capacity values by subtracting the value obtained under non-binding conditions. The column was cleaned and regenerated with a $0.1 \mathrm{M} \mathrm{NaOH}$ solution.

\section{Results and discussion}

\subsection{Binding of pUC19 pDNA to the 16mer peptide monitored by SPR}

In previous work, a 186 bp dsDNA fragment of pUC19 template and a 64mer peptide ligand containing the complete LacI DNA binding domain (helix I - helix IV) was studied [52]. The feasibility study using the 64mer peptide ligand for pDNA purification was positive, however the yield was low owing to the strong affinity between 64mer peptide and pDNA being of the order of a dissociation constant of $5.7 \times 10^{-11} \mathrm{M}[23,34]$. We reasoned that deletion of some non-contributing amino acids could create a peptide that would retain the DNA binding properties of the Lac repressor.

A 16mer peptide was then designed to mimic helix II binding in the Lac repressor protein. We have previously described the kinetics of the 16 mer peptide compared to the 64 mer (Helix I to IV), 47mer (Helix I to III), 27mer (Helix I to II) and the designed 16mer (portion of Helix II) [48]. Here we fully described the properties of the 16 mer peptide and its behavior during chromatographic purification of target pDNA. Fig.1 shows the amino acid sequence of the potential DNA-binding synthetic peptide 16 mer, corresponding to residues $19-26$ of the DNA binding domain of LacI protein [33]. The 16mer peptide was immobilized to a BIAcore sensor chip using a thiol coupling reagent PDEA as shown in Fig. 3. 
Plasmid pUC19 was applied to the 16mer peptide immobilized on the sensor chip surface and the interaction was monitored in real-time by surface plasmon resonance- based BIAcore system. Plotting the response (RU) against time (seconds) during the course of an interaction provides a quantitative measure of the progress of the interaction. A typical sensorgram is shown in Fig. 4, indicating the binding of pUC19 to immobilized LacI peptide. Between each run, the chip surface was regenerated using $1 \mathrm{M} \mathrm{NaCl}, \mathrm{pH} 10$.

Figure 4 presents the comparison of subtracted sensorgram obtained after the injections of a series of pUC19 concentration over the 16 mer peptide surface and blank surface with a $600.1 \mu \mathrm{g} / \mathrm{ml}$ control plasmid pEGFP-N1. As shown in Fig. 4, the increase in response units was observed after pUC19 loading following subtraction of the blank flowcell 1. A surface response to the 16mer peptide was observed with pUC19 (19.2 RU at $0.05 \mu \mathrm{g} / \mathrm{ml}$ pUC19) while no difference was observed after injection of plasmid pEGFP-N1 at a high concentration $(600.1 \mu \mathrm{g} / \mathrm{ml})$. This indicates that 16 mer peptide specifically interacted with pUC19 since it had no binding to plasmid pEGFP$\mathrm{N} 1$ which did not contain $l a c \mathrm{O}$ region.

As shown in the sensorgram (Fig. 4), pUC19 had a very rapid on-rate that is characteristic of protein- or peptide-DNA associations and often ascribed to conformational changes within the DNA or protein/peptide upon interaction. Such kinetic events may involve non-specific electrostatic associations (e.g. with the phosphate backbone) prior to specific sequence interactions with the pUC19 operator sequence as suggested [53].

The adsorption isotherm (Fig. 5) is Langmuir in nature [48], implying a strong 1:1 interaction between pUC19 molecules and the 16mer peptide immobilized on the sensor chip. The isotherm 
has a sharp initial rise, suggesting a high affinity between pUC19 molecules and the 16mer peptide. In addition, the dissociation constant of the binding (shown as $R_{\max } / 2$ in Fig. 5) between 16 mer peptide and pUC19 was $5.0 \pm 0.5 \times 10^{-8} \mathrm{M}$, which indicates that it has an optimum affinity for pDNA purification, which is ideally within the range of $10^{-8}$ and $10^{-6} \mathrm{M}$ and this could be tested in the chromatographic system.

\subsection{Effect of different buffer on the binding between pDNA and peptide}

As shown in Table 1, the different standard DNA buffers (all at 7.4), with varied ionic strength, have some effect on the binding between pDNA and 16mer peptide. The 16mer - pUC19 interaction had the strong affinity $\left(3.0 \pm 0.3 \times 10^{-9} \mathrm{M}, I=110 \mathrm{mM}\right)$ in a lower ionic strength Tris. $\mathrm{HCl}$ buffer $(100 \mathrm{mM} \mathrm{NaCl})$, followed by HBS buffer $\left(5.0 \pm 0.5 \times 10^{-8} \mathrm{M}, I=150 \mathrm{mM}\right)$, with the weakest affinity in PBS buffer $\left(6.5 \pm 0.3 \times 10^{-8} \mathrm{M}, I=161 \mathrm{mM}\right)$. However, these values are all within a reasonable and close range and from these indications the weaker affinity of the PBS buffer was selected as suitable for the chromatography work.

\subsection{Packed bed adsorption of pure pUC19 to the 16mer peptide}

Purified pUC19 $(100.2 \mu \mathrm{g}, 0.2 \mathrm{ml})$ was loaded onto the $4 \mathrm{ml}$ monolith column immobilized with the 16 mer peptide at a flow rate of $0.5 \mathrm{ml} / \mathrm{min}$, followed by a washing step with $0.01 \mathrm{M}$ PBS buffer, $\mathrm{pH}$ 7.4. The subsequent elution of bound pDNA used a higher salt phosphate buffer ( $0.01 \mathrm{M}$ phosphate, $2 \mathrm{M} \mathrm{NaCl}$ ) and a faster flow rate of $1.0 \mathrm{ml} / \mathrm{min}$. The $\mathrm{OD}_{260 \mathrm{~mm}}$ and buffer $\mathrm{B}$ signal from the Duoflow biological chromatography are plotted against elution time in Figure 6, showing that there was only 
a single product peak during the prolonged elution phase. This indicates that the 16 mer peptide had sufficient affinity to capture the pUC19 DNA under chromatography rigors.

An ethidium bromide agarose electrophoresis gel (Fig.7) shows that the single eluted pUC19 product forms a discrete DNA band with no signs of degradation or breakdown products. Densitometry analysis of the gel bands shows the eluted fraction comprises $96 \%$ supercoiled pDNA. This indicates that the 16mer peptide has shown preference for adsorption of the supercoiled pDNA over linear and open circular forms of pDNA (Inset image of Fig. 6). The eluted pDNA (lane 2 in Fig. 7) was only in supercoiled form. As can be seen in lane 1 in Fig. 7, endonuclease digestion gel of the purified pDNA shows that an EcoRI cut supercoiled pDNA into a relaxed linear form, migrating differently to the expected supercoiled pDNA (ca. $3 \mathrm{kbp} c f$ ca. $1.8 \mathrm{kbp}$ ) using the digestion method [54].

\subsection{Dynamic binding capacity of pDNA}

Breakthrough curves provide information on the dynamic binding capacity of a separation medium. The pDNA solution was pumped through the monolithic column at a defined flow rate, and the absorbency of the outlet at $260 \mathrm{~nm}$ was measured. A breakthrough curve is shown in Fig.8 and dynamic binding capacity was extracted manually by determination of the volume corresponding to $50 \%$ breakthrough. Multiplication of this volume by the initial feed concentration gives the dynamic binding capacity. At $50 \%$ breakthrough the binding capacity was found to be $0.39 \mathrm{mg} \mathrm{pDNA} / \mathrm{ml}$ monolith immobilized with the 16 mer peptide. This is lower than for anion exchange monolith (about $6.0 \mathrm{mg} / \mathrm{ml}$ ). However, it should be highlighted that anionic media has only a moderate level of active discrimination between RNA, gDNA and other contaminating cellular debris, and cannot 
readily discriminate two distinct pDNA species as demonstrated with the 16mer and the pEGFP-N1 control plasmid. Furthermore, neither polymerization nor immobilization conditions for peptide capture were optimized for maximal yield, which could greatly increase the capacity for scaled purification. Hence the presented data indicate that the 16 mer peptide immobilized monolith can be employed as a novel stationary phase for low contaminant chromatographic purification of pDNA and further studies will investigate possible advantages over the existing chromatographic supports, especially beyond the laboratory scale.

\section{Conclusions}

The specific capture of pDNA was achieved using a new type of affinity ligand - the 16mer LacIbased peptide. This study enables a novel approach to address pDNA purification problems using the DNA binding properties of LacI. Initially peptide-DNA affinities were examined using a surface Plasmon resonance Biacore system before peptide immobilisation onto a monolith support. In the case of designed peptides, we were able to control the orientation of the ligand to its target molecule in the Biacore system. The dissociation constant of the binding between the 16 mer peptide and pDNA is $5.0 \pm 0.5 \times 10^{-8} \mathrm{M}$, indicating that the 16 mer peptide potently binds pDNA within an optimum dissociation constant for process rigors (within the range of $10^{-8}-10^{-6} \mathrm{M}$ ). This was also confirmed using pUC19 applied on a customized monolith chromatography support functionalised with the 16 mer peptide. There was only one product peak appearing in the extended elution phase, comprising highly pure supercoiled pDNA from the single chromatographic unit operation. The agarose gel of the fraction confirmed the peak was pDNA and endonulease digest showed that it was supercoiled pDNA. The results imply that supercoiled pDNA was preferentially captured in a single chromatographic unit step. Therefore, this biomimetic approach utilising only a portion of the 
LacI protein as a designed ligand to purify pDNA is presented as a suitable alternative for pDNA purification.

\section{Acknowledgements}

This work was supported by VESKI, the Victorian Endowment for Science, Knowledge and Information. Y. Han also acknowledges scholarships from IPRS/MGS.

\section{References}

[1] Bouchie A. Box 1 FDA, NCI collaborate to identify biomarkers for cancer trials Nature Biotechnology 2003; 21:718.

[2] Danquah MK, Forde GM. Rapid therapeutic plasmid DNA isolation: Addressing the looming vaccine crisis. BioForum, vol. 10, 2006. p.24.

[3] Davis HL. Plasmid DNA expression systems for the purpose of immunization. Current Opinion in Biotechnology 1997;8:635.

[4] Diogo MM, Ribeiro SC, Queiroz JA, Monteiro GA, Tordo N, Perrin P, Prazeres DM. Production, purification and analysis of an experimental DNA vaccine against rabies. J. of Gene Medicine 2001;3:577.

[5] Forde GM. Rapid-response vaccines-does DNA offer a solution? Nature Biotechnology 2005;23:1059.

[6] Fukumoto S, Tamaki Y, Okamura M, Bannai H, Yokoyama N, Suzuki T, Igarashi I, Suzuki $\mathrm{H}$, Xuan X. Prime-boost immunization with DNA followed by a recombinant vaccinia virus expressing P50 induced protective immunity against Babesia gibsoni infection in dogs. Vaccine $2007 ; 25: 1334$. 
[7] Johansen P, Raynaud C, Yang M. Anti-mycobacterial immunity induced by a single injection of M-leprae Hsp65-encoding plasmid DNA in biodegradable microparticles. Immunol. letters 2003;90:81.

[8] Michel ML, Davis HL, Schleef M. DNA-Mediated immunization to the hepatitis-B surface antigen in mice-aspects of the humoral response mimic hepatitis-B viral infection in humans. Proceedings of the national academy of science of the USA 92. USA, 1995. p.5307.

[9] Wolff JA, Malone RW, Williams P, Chong W, Acsadi G, Jani A, Felgner PL. Direct gene transfer into mouse muscle in vivo Science 1990;247:1465

[10] FDA Fada. Guidance for industry (draft guidance): consideration for plasmid DNA vaccines for infectious disease indications. www.fda.gov/cber/gdlns/plasdnavac.htm, . FDA office of communication, Training and manufacturers assistance (HFM-40) 2006;1401 Rockville Pike, MD 20852-1448 USA.

[11] Diogo MM, Queiroz JA, Prazeres DMF. Chromatography of plasmid DNA. Journal of Chromatography A 2005;1069:3.

[12] Levy MS, O'Kennedy RD, Ayazi-Shamlou P, Dunnill P. Biochemical engineering approaches to the challenges of producing pure plasmid DNA. Trends Biotechnol. 2000;18:296.

[13] Stadler J, Lemmens R, Nyhammar T. Plasmid DNA purification. J. of Gene Medicine 2004;6:54

[14] Ferreira GN. Chromatographic approaches in the purification of plasmid DNA for therapy and vaccination. Chem. Eng. Technol. 2005;28:1285.

[15] Urthaler J, Buchinger W, Necina R. Industrial cGMP Purification of Pharmaceutical Grade Plasmid-DNA. Chemical Engineering and Technology 2005;28 1408.

[16] Urthaler J, Buchinger W, Necina R. Improved downstream process for the production of plasmid DNA for gene therapy. Acta Biochimica Polonica 2005a;52:703. 
[17] Urthaler J, Schlegl R, Podgornik A, Strancar A, Jungbauer A, Necina R. Application of monoliths for plasmid DNA purification: Development and transfer to production. Journal of Chromatography A 2005b;1065:93.

[18] Labrou NE. Design and selection of ligands for affinity chromatography. J.of Chromatography B 2003:67.

[19] Schluep T, Cooney CL. Purification of plasmid DNA by triplex affinity interactions. Nucleic Acids Res. 1998;26:4524.

[20] Wils P, Escriou V, Warnery A, Lacroix F, Lagneaux D, Ollivier M, Crouzet J, Mayaux JF, Scherman D. Efficient purification of plasmid DNA for gene transfer using triple-helix affinity chromatography. Gene Therapy 1997;4:323.

[21] Woodgate J, Palfrey D, Nagel DA, Hine AV, Slater NKH. Protein-Mediated isolation of plasmid DNA by a Zinc finger-glutathione $\mathrm{S}$-Transferase affinity linker. Biotechnology and bioengineering 2002;79:450.

[22] Darby RAJ, Hine AV. LacI-mediated sequence-specific affinity purification of plasmid DNA for therapeutic applications. The FASEB Journal 2005; 19:801.

[23] Forde GM, Ghose S, Slater NKH, Hine AV, Darby AJ, Hitchcock AG. LacO-LacI interaction in affinity adsorption of plasmid DNA. Biotechnology and bioengineering 2006;95:67.

[24] Kumar A, Galaev IY, Mattiasson B. Purification of Lac repressor protein using polymer displacement and immobilization of the protein. Bioseparation 1999;8:307.

[25] Hasche A, Voß C. Immobilisation of a repressor protein for binding of plasmid DNA. Journal of Chromatography A 2005;1080:76.

[26] Chakerian AE, Matthew KS. Effect of Lac repressor oligomerization on regulatory outcome. Mol. Microbiol. 1992;6:963. 
[27] Barkley MD, Bourgeois S. Repressor recognition of operator and effectors. NY: Cold spring harbor laboratory press, 1980.

[28] Kisters-Woike B, Lehming N. A model of the Lac repressor-operator complex based on physical and genetic data. European Journal of Biochem 1991;198:411.

[29] Markiewicz P, Kleina LG. Genetic studies of the Lac repressor XIV. analysis of 4000 altered Escherichia coli Lac repressors reveals essential and non-essential residues, as well as "spacers" which do not require a specific sequence. J. of Mol. Biol. 1994; 240:421.

[30] Steitz TA. Structural studies of protein-nucleic acid interaction: the sources of sequencespecific binding Quart. Rev. Biophys. 1990;23:205.

[31] Barker A, Fickert R. Operator search by mutant Lac repressors. J. Mol. Biol. 1998;278:549.

[32] Bell CE, Lewis M. The Lac repressor: a second generation of structural and functional studies. Current Opinion in Structural Biology 2001;11:19.

[33] Lewis M, Chang G, Horton NC, Kercher MA, Pace HC, Schumacher MA, Brennan RGL, P. Crystal structure of the lactose operon repressor and its complex with DNA and inducer. Science $1996 ; 271: 1247$

[34] Ghose S, Forde GM, Slater NKH. Affinity adsorption of plasmid DNA. Biotechnol. Prog. $2004 ; 20: 841$

[35] Gasteiger EHC, Gattiker A, Duvaud S, Willkins MR, Appel RD, Bairoch A. Protein identification and analysis tools on the ExPASy server. The proteomics protocols handbook. In: Walker JM, editor. Humana Press, 2005. p.571.

[36] Dinner AR, Ŝali A, Smith LJ, Dobson CM, Karplus M. Understanding protein folding via free energy surfaces from theory and experiment. Trends in Biochemical Sciences 2000;25:331.

[37] Kyte J, Doolottle RF. A simple method for displaying the hydropathic character of a protein. J. Mol. Biol. 1982;157:105. 
[38] Diogo MM, Queiroz JA, Prazeres DMF. Studies on the retention of plasmid DNA and Escherichia coli nucleic acids by hydrophobic interaction chromatography. . Bioseparation 2001;10:211.

[39] Diogo MM, Queiroz JA, Monteiro GA, Martins SA, Ferreira GN, Prazeres DM. Purification of a cystic fibrosis plasmid vector for gene therapy using hydrophobic interaction chromatography. biotchnol. bioeng. 2000;68:576.

[40] Branovic K, Buchacher A, Barut M, Strancar A, Josic D. Application of semi-industrial monolithic columns for downstream processing of clotting factor IX. Journal of Chromatography B 2003;790:175.

[41] Branovic K, Forcic D, Ivancic J, Strancar A, Barut M, Kosutic Gulija T, Zgorelec R, Mazuran R. Application of short monolithic columns for fast purification of plasmid DNA. Journal of Chromatography B 2004;801:331.

[42] Jungbauer A, Hahn R. Monoliths for fast bioseparation and bioconversion and their applications in biotechnology. Journal of Separation Science 2004;27:767.

[43] Kalashnikova I, Ivanova N, Tennikova T. Development of a strategy of influenza virus separation based on pseudoaffinity chromatography on short monolithic columns. Analytical Chemistry 2008;80:2188.

[44] Platonova GA, Tennikova TB. Affinity processes realized on high-flow-through methacrylate-based macroporous monoliths. Journal of Chromatography A $\quad 2005 ; 1065: 19$.

[45] Diogo MM, Queiroz JA, Prazeres DMF. Assessment of purity and quantification of plasmid DNA in process solutions using high-performance hydrophobic interaction chromatography. Journal of Chromatography A 2003;998:109.

[46] Chaga GS. Twenty-five years of immobilized metal ion affinity chromatography: past, present and future. J Biochem Biophys Methods 2001;49. 
[47] Lemmens R, Olsson U, Nyhammar T, Stadler J. Supercoiled plasmid DNA: selective purification by thiophilic/aromatic adsorption. Journal of Chromatography B 2003;784:291.

[48] Han Y, Gras SL, Forde GM. Binding properties of peptidic affinity ligands for plasmid DNA capture and detection. AIChE Journal, 2009; 55: 505.

[49] Karlsson R, Falt A. Experimental design for kinetic analysis of protein-protein interaction with surface plasmid resonance biosensors. J. of Immunological Methods 1997;200:121.

[50] Hermanson G, Mallia K, Smith P. Immobilized Affinity Ligand Techniques (book), ISBN 0-12-342330-9, Adademic Press Inc. 1992; 131-268.

[51] Han Y, Forde GM. Single Step Purification of Plasmid DNA Using Peptide Ligand Affinity Chromatography. J. of Chromatography B 2008; 874:21-26.

[52] Akdi K, Vilaplana RA, Kamah S, González-Vílchez F. Effects of Tris and Hepes buffers on the interaction of palladium-disminopropane complexes with DNA. Journal of Inorganic Biochemistry 2005;99:1360.

[53] Charalampos ea. Structure and flexibility adaptation in nonspecific and specific proteinDNA complexes. Science 2004;305:386.

[54] Tweedie JW, Stowell KM. Quantification of DNA by agarose gel electrophoresis and Analysis of the topoisomers of plasmid and M13 DNA following treatment with a restriction endonuclease or DNA topoisomerase I. Biochemistry and Molecular Biology Education 2005;33:28. [55] Raghava GPS. Protein secondary structure prediction using nearest neighbor and neural network approach. CASP4 2000:75. 
Table 1 Effect of binding buffers on the kinetics of the interaction of peptides designed - plasmid DNA

Figure legends:

Figure 1. Structure of the designed 16mer peptide. Termini: $\mathrm{H}-\quad-\mathrm{OH}$. The peptide comprises an $\mathrm{N}$-terminal cysteine for chemical manipulation in the designer sequence and a C-terminal fragment from helix II of the Lac repressor. Secondary structure was predicted using the Advanced Protein Secondary Structure Prediction Server (APSSP) (http://imtech.res.in/raghava/apssp/) employing a nearest neighbor and neural network approach [55]. The nomenclature is in Table $(\mathrm{H}=$ helix; $\mathrm{E}=$ Strand; $\mathrm{C}=$ Coil) and probability of correct assignment shown.

Figure 2. The N-terminal DNA binding domain (residues 1-60) of LacI is shown with helix II present in red binding to the minor groove of the lac $\mathrm{O}$ sequence (protein data base: 1JWL is the code for the structure of the protein and DNA complex). Figure generated using Molsoft ICM Browser (version 3.4-8f, MolSoft L.L.C.). A large contribution of bonding can be seen with the helix, which penetrates the major DNA binding groove.

Figure 3. Sensorgram of immobilisation of 16 mer peptide by thiol ligand method. Four stages in the immobilization procedure were indicated: NHS/EDC, activation of sensor chip by NHS/EDC; PDEA, modification by PDEA; Ligand, immobilization of ligand (16mer peptide); L-cysteine, deactivation and washing with $50 \mathrm{mM} \mathrm{L-cysteine} \mathrm{and} 1 \mathrm{M} \mathrm{NaCl} . \Delta \mathrm{R}$ indicates the amount of ligand immobilized.

Figure 4. Comparison of subtracted sensorgram obtained after the injections of a series of pUC19 concentration over the 16 mer peptide surface and blank surface with a $600.1 \mu \mathrm{g} / \mathrm{ml}$ control plasmid 
pEGFP-N1. The increase in response unit was observed after pUC19 loading while no change with pEGFP - N1 loading.

Figure 5. Adsorption isotherm for plasmid pUC19 binding to 16 mer peptide immobilized to a Biacore $\mathrm{C} 1$ chip measured in response units. The $\mathrm{C} 1$ chip was equilibrated before each run with HBS buffer pH7.4 and regenerated after each run. The amount of bound plasmid DNA was estimated by monitoring the surface plasmon resonance signal (RU) at a fixed time just before the end of injection. $R_{\max } / 2=K_{D}$, So the dissociation constant of the binding between pDNA and 16mer peptide was $0.5 \times 10^{-7} \mathrm{M}=5 \times 10^{-8} \mathrm{M}$.

Figure 6. Chromatogram of plasmid pUC19 loaded on 16mer peptide immobilised on self-made monolith. Bound plasmid DNA was eluted using PBS buffer (0.01 M PBS, KCl 0.0027M; pH7.4) with additional $\mathrm{NaCl}$ (final concentration: $1 \mathrm{M}$ ). Inset image: $0.8 \%$ Ethidium Bromide agarose

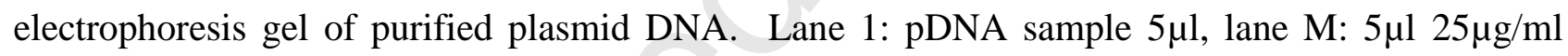
$1 \mathrm{kbp}$ DNA ladder. The clear apparent band is supercoiled (SC) pDNA.

Figure 7a. Agarose electrophoresis gel of plasmid DNA with 16 mer peptide immobilised on a $4 \mathrm{ml}$ customized monolith (negative agarose gel). M: 1kb DNA marker; lanes 1 and 2: eluted pDNA; Figure 7b. Restriction endonuclease digestion of purified pDNA. EcoRI cut supercoiled pDNA into linear pDNA (ca. 3kbp) using the method described before [54].

Figure 8. Breakthrough curve of pDNA using 16mer peptide - monolith chromatography.69.9 $\mu \mathrm{g} / \mathrm{ml}$ of plasmid in $0.01 \mathrm{M}$ PBS buffer was loaded in the breakthrough experiment. 


\section{No Helix I, Turn, Loop or Helix III}

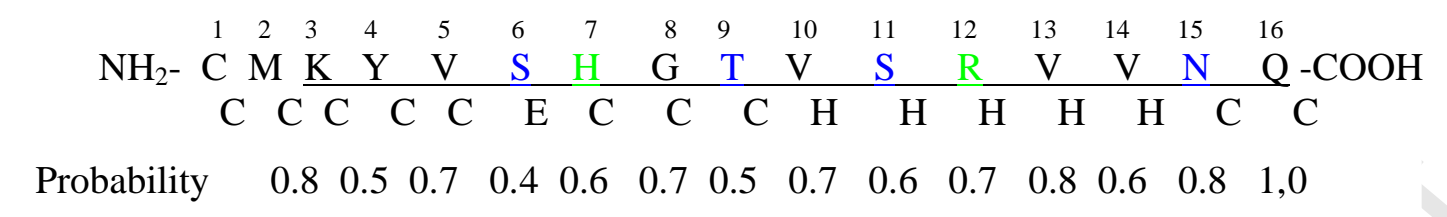

Helix II

Figure 1. Structure of designed 16mer peptide. Termini: $\mathrm{H}-\quad-\mathrm{OH}$. The peptide comprises an $\mathrm{N}$-terminal cysteine for chemical manipulation in the designer sequence and a C-terminal fragment from helix II of the lac repressor. Secondary structure was predicted using the Advanced Protein Secondary Structure Prediction Server (APSSP) (http://imtech.res.in/raghava/apssp/) employing a nearest neighbor and neural network approach [55]. The nomenclature is in CASP format $(\mathrm{H}=$ helix; $\mathrm{E}=\mathrm{Strand} ; \mathrm{C}=\mathrm{Coil})$ and probability of correct assignment shown.

Flow through and wash

Elution 


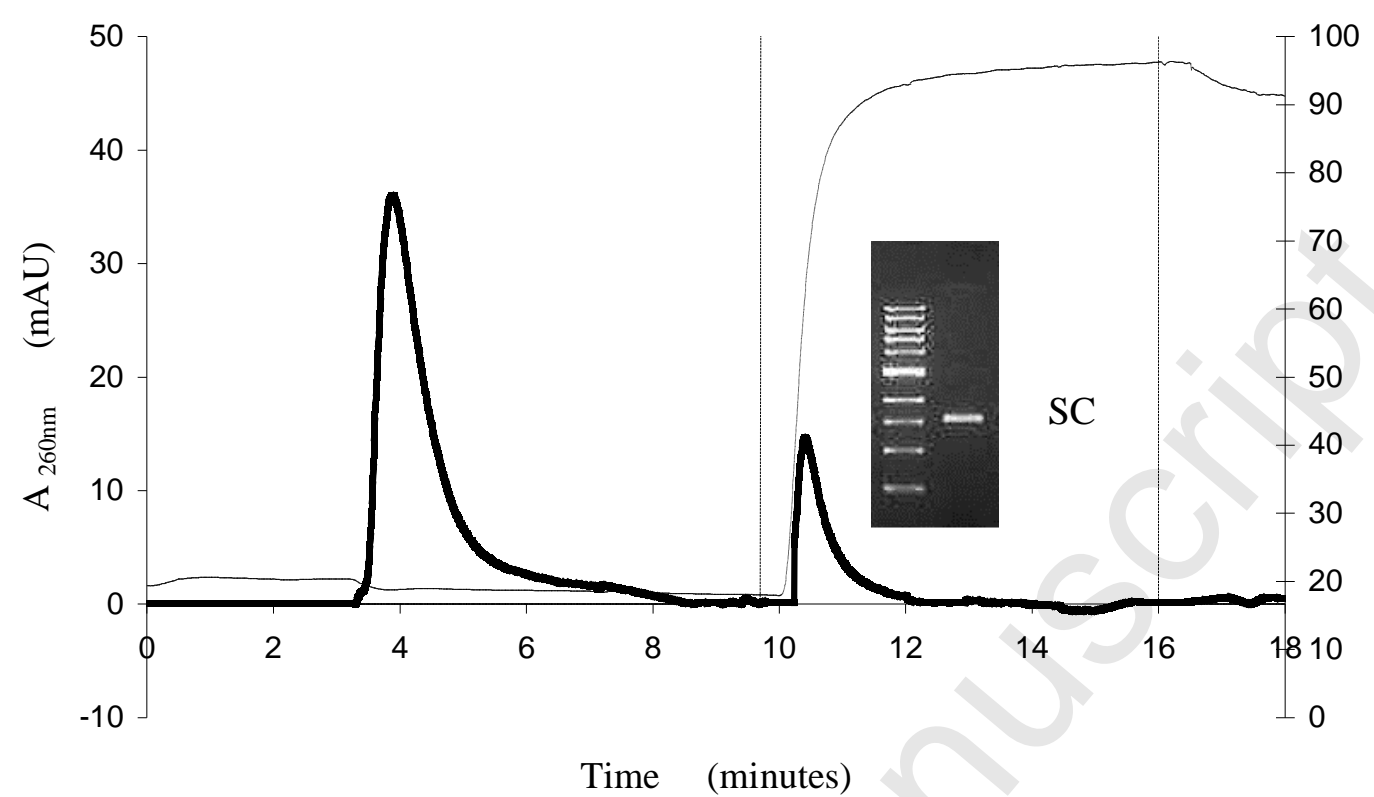

Figure 6. Chromatogram of plasmid pUC19 loaded on 16mer peptide immobilised on self-made monolith. Bound plasmid DNA was eluted using PBS buffer (0.01 M PBS, $\mathrm{KCl}$ 0.0027M; pH7.4) with additional $\mathrm{NaCl}$ (final concentration: $1 \mathrm{M}$ ). Inset image: $0.8 \%$ Ethidium Bromide agarose electrophoresis gel of purified plasmid DNA. Lane

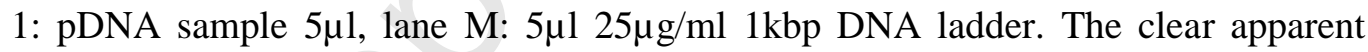
band is supercoiled (SC) pDNA.

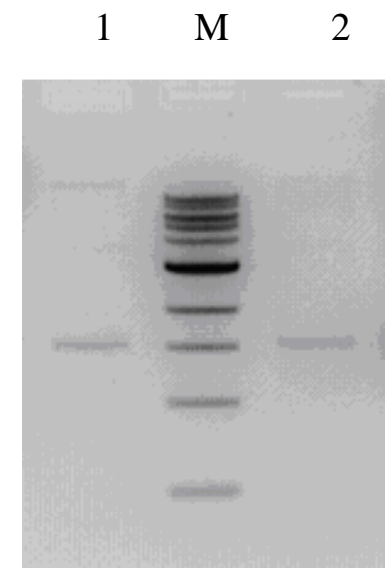

$\mathrm{b}$ 
Figure 7a. Agarose electrophoresis gel of plasmid DNA with 16mer peptide immobilised on a $4 \mathrm{ml}$ customized monolith (negative agarose gel). M: $1 \mathrm{~kb}$ DNA marker; lanes 1 and 2: eluted pDNA; Figure 7b. Restriction endonuclease digestion of purified pDNA. EcoRI cut supercoiled pDNA into linear pDNA (ca. 3kbp) using the method described before[54]. 


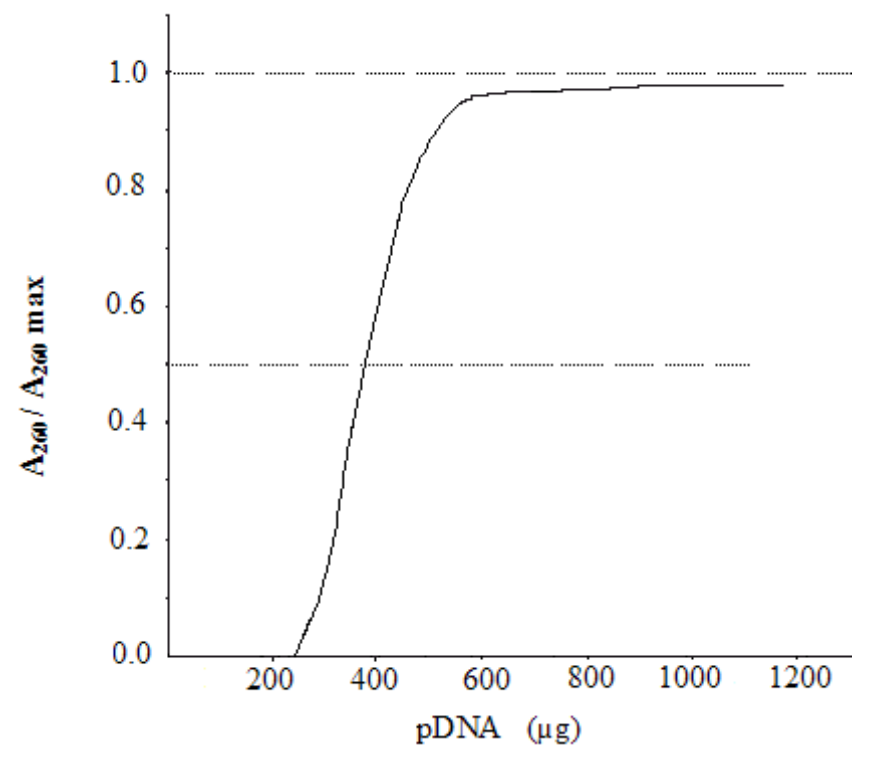

Figure 8. Breakthrough curve of plasmid DNA using 16mer peptide - monolith chromatography. $69.9 \mu \mathrm{g} / \mathrm{ml}$ of plasmid in $0.01 \mathrm{M}$ PBS buffer was loaded in the breakthrough experiment. 


\section{Flow through and wash Elution}

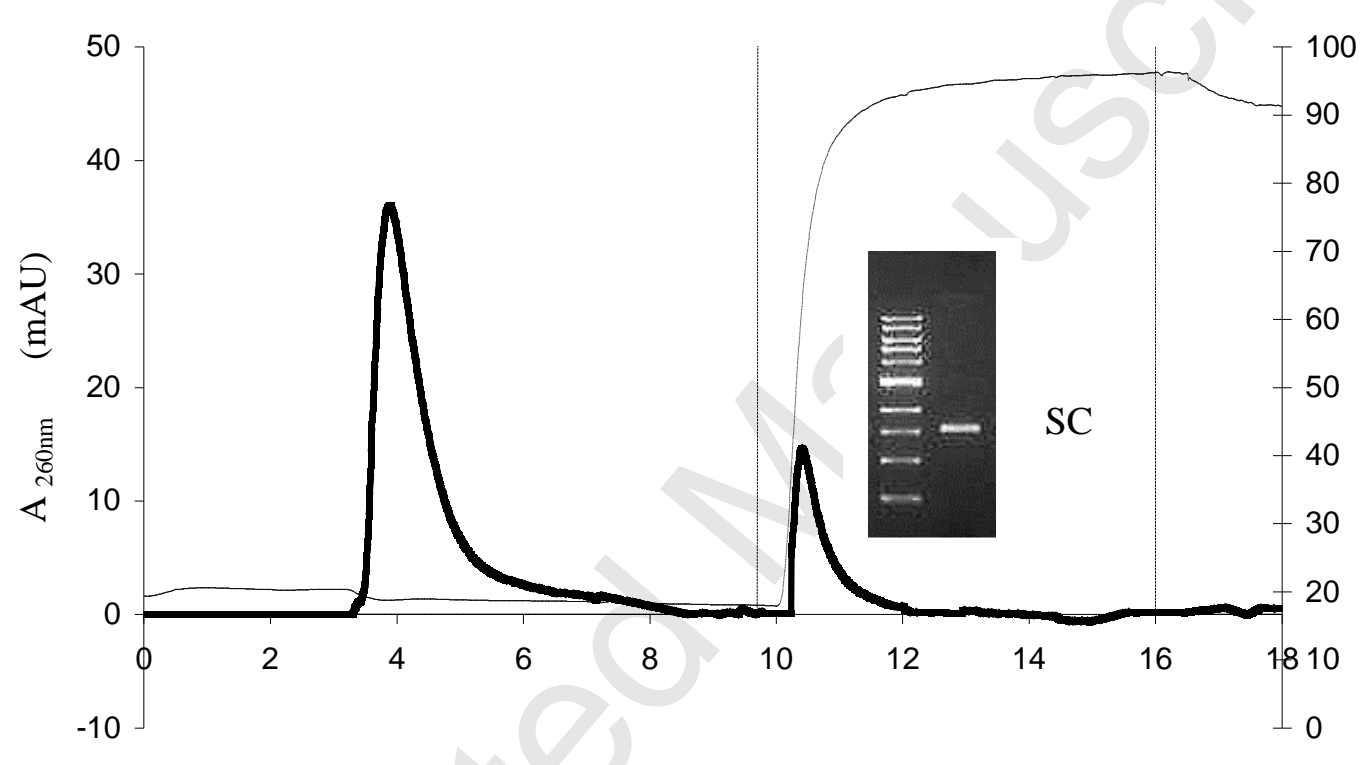

Time (minutes)

Figure 6. Chromatogram of plasmid pUC19 loaded on 16mer peptide immobilised on self-made monolith. Bound plasmid DNA was eluted using PBS buffer (0.01 M PBS, $\mathrm{KCl}$ 0.0027M; $\mathrm{pH} 7.4$ ) with additional $\mathrm{NaCl}$ (final concentration: $1 \mathrm{M}$ ). Inset image: $0.8 \%$ Ethidium Bromide agarose electrophoresis gel of purified plasmid DNA. Lane 1: pDNA sample $5 \mu 1$, lane M: $5 \mu 125 \mu \mathrm{g} / \mathrm{ml} 1 \mathrm{kbp}$ DNA ladder. The clear apparent band is supercoiled (SC) pDNA. 
a

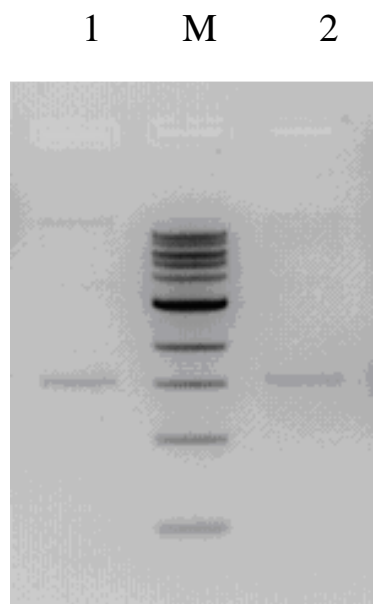

b

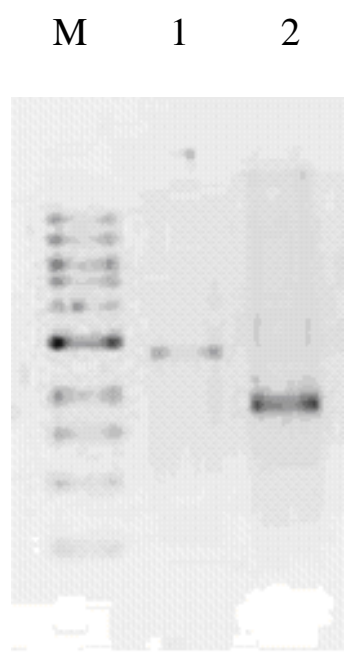

Figure 7a. Agarose electrophoresis gel of plasmid DNA with 16mer peptide immobilised on a $4 \mathrm{ml}$ customized monolith (negative agarose gel). M: 1kb DNA marker; lanes 1 and 2: eluted pDNA; Figure 7b. Restriction endonuclease digestion of purified pDNA. EcoRI cut supercoiled pDNA into linear pDNA (ca. 3kbp) using the method described before[54]. 


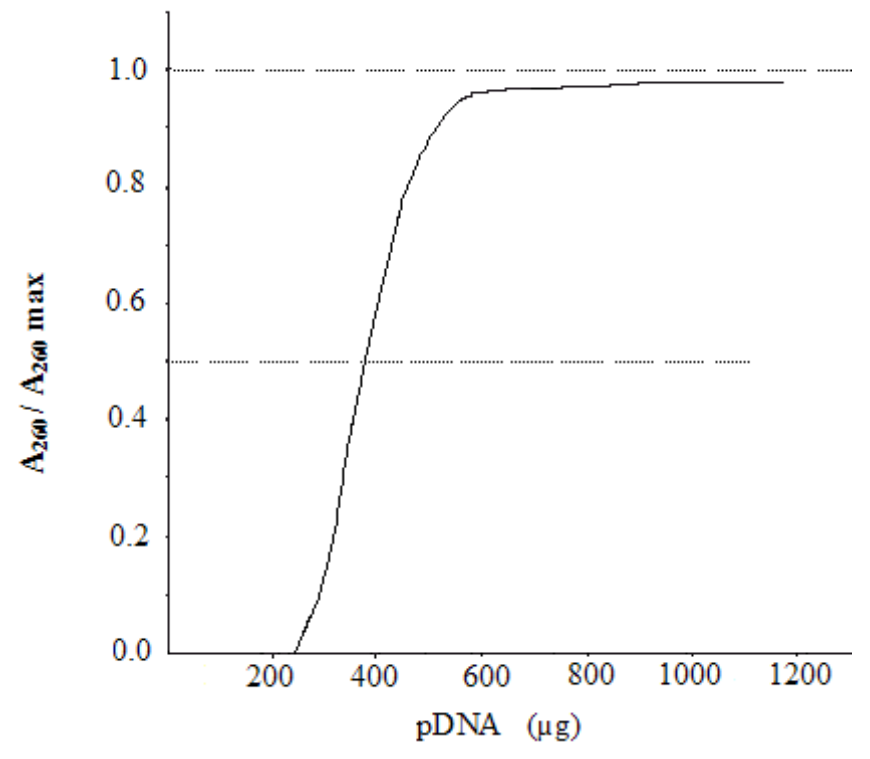

Figure 8. Breakthrough curve of plasmid DNA using 16mer peptide - monolith chromatography. $69.9 \mu \mathrm{g} / \mathrm{ml}$ of plasmid in 0.01M PBS buffer was loaded in the breakthrough experiment. 